\title{
Review
}

\section{Lack of Equity in the Cardiology Physician Workforce: A Narrative Review and Analysis of the Literature}

\author{
Michelle Keir, MD, MSc, ${ }^{a}$ Chanda McFadden, MSW, RSW, ${ }^{b}$ Shannon Ruzycki, MD, MPH, ${ }^{c}$ \\ Sarah Weeks, MD, ${ }^{a}$ Michael Slawnych, MD, ${ }^{\mathrm{d}}$ R. Scott McClure, MD, SM, ${ }^{\mathrm{e}}$ Vikas Kuriachan, MD, ${ }^{a}$ \\ Paul Fedak, MD, PhD, ${ }^{\mathrm{e}}$ and Carlos Morillo, $\mathrm{MD}^{\mathrm{a}}$ \\ ${ }^{a}$ Section of Cardiology, Department of Cardiac Sciences, Cumming School of Medicine, Libin Cardiovascular Institute, University of Calgary, Calgary, Alberta, Canada \\ ${ }^{b}$ Department of Allied Health, Alberta Health Services, Calgary, Alberta, Canada \\ ${ }^{c}$ Department of Medicine, Cumming School of Medicine, University of Calgary, Calgary, Alberta, Canada \\ ${ }^{d}$ Section of Palliative Care and Cardiology, Libin Cardiovascular Institute, University of Calgary, Calgary, Alberta, Canada \\ 'Section of Cardiac Surgery, Department of Cardiac Sciences, Cumming School of Medicine, Libin Cardiovascular Institute, University of Calgary, Calgary, Alberta, \\ Canada
}

\begin{abstract}
The gender and racial diversity in the cardiology workforce in Canada does not reflect that of the population we serve. As social awareness of the principles of equity, diversity, and inclusion rises, our profession must rise to meet the challenges they present. We detail contemporary examples of publication bias in the cardiac sciences literature and describe the factors that led to oversight in the peer-review process. We performed a narrative review to summarize the published literature on equity and diversity among cardiac physicians. We also summarize the challenges faced by women and racial-minority physicians when pursuing and thriving in a career in cardiology, and the systemic
\end{abstract}

Despite equal numbers of women and men graduating from medical schools in Canada, only $22 \%$ of cardiologists are women, and even fewer enter interventional specialties. ${ }^{1}$ Less than $10 \%$ of cardiac surgeons are women. ${ }^{1}$ More than $50 \%$ of cardiologists in the US are White. ${ }^{2}$ Black, Latino, and Indigenous populations are significantly underrepresented in the cardiology workforce. ${ }^{2}$ Even a cursory evaluation of the cardiology workforce shows that we, as a profession, do not reflect the diversity of the population we serve. There is no evidence to suggest that members of equity-deserving groups are uninterested in the practice of cardiac medicine. On the contrary, ample evidence

Received for publication July 9, 2021. Accepted September 20, 2021.

Ethics Statement: This article adheres to all relevant ethical guidelies. Corresponding author: Dr Michelle Keir, Peter Lougheed Centre, 3500 26th Ave, NE Calgary, Alberta T1Y 6J4, Canada. Tel: 403-943-4504; Fax: 403-291-6814.

E-mail: michelle.keir@albertahealthservices.ca

See page 185 for disclosure information.

\section{RÉSUMÉ}

Au Canada, la diversité des genres et des races au sein de la maind'œuvre en cardiologie ne reflète pas celle qui existe dans la population que nous servons. La prise de conscience sociale des principes d'équité, de diversité et d'inclusion gagne du terrain, et notre profession doit se montrer à la hauteur des défis qui s'y rattachent. Nous abordons des exemples contemporains de biais de publication dans la littérature cardiologique et décrivons les facteurs qui ont mené à des omissions dans le processus d'examen par les pairs. Une revue narrative de la littérature publiée sur l'équité et la diversité parmi les cardiologues nous a permis de résumer l'information publiée sur le

indicates the presence of gender discrimination, pregnancy discrimination, racial bias, and sexual harassment in our profession. ${ }^{3-6}$ Unsurprisingly, medical students who experience discrimination or harassment during their clerkship rotations are much less likely to select those specialties, suggesting that a high prevalence of discrimination may perpetuate the observed underrepresentation. ${ }^{7}$ Obesity bias, ableism, colonialism, and heteronormativity in cardiac sciences have yet to be examined, although they undoubtedly exist.

It is no longer acceptable to disregard inequity. The standards of professionalism are changing rapidly, and we fear our colleagues, and our profession, will be left behind. ${ }^{8}$ Papers are being retracted and careers limited because of a dearth of understanding of key social justice principles among cardiac professionals., ${ }^{9}, 10$ Even more worrying is that the lack of diversity and representation affects patient care. ${ }^{11} \mathrm{We}$ present a narrative review of the literature and a primer on important concepts with which each cardiac sciences professional should be acquainted. 
barriers to their success. In the past decade, social justice movements have advanced. Professionalism standards are changing, and awareness and understanding of these advances in terminology is imperative for all physicians. In this review, we summarize key language and concepts, with cardiology-specific examples, and propose a new paradigm of professionalism.

\section{Methods}

We conducted a MEDLINE search using permutations of the following keywords: cardiology, cardiologists, cardiology workforce, career choice, health equity, equity, gender equity, racial equity, discrimination, pregnancy, training, women in cardiology, disparities, diversity, and medical education. Original research papers on cardiology workforce equity, and position papers by professional societies or working groups, were included. Publications providing commentary alone were excluded. After review of 176 citations, and a hand-search of the references of papers that met the inclusion criteria, we included 20 articles published prior to May 2021. We identified the following 5 themes: editorial and review bias in cardiac sciences, pregnancy discrimination, gender diversity, and racial diversity in cardiology. The literature is summarized below in a narrative review.

\section{Editorial bias in cardiac sciences}

In the past 2 years, 3 major journals were forced to retract or apologize for peer-reviewed papers, owing to their inclusion of offensive material. One was the Journal of Vascular Surgery. A paper that peddled sexist and outdated tropes of medical professionalism created an uproar and prompted the \#medbikini social media campaign. ${ }^{9,12}$ Similarly, an editorial rife with racist themes was retracted from the Journal of the American Heart Association after public and social media outcry. ${ }^{10}$ In commentary accompanying the retraction, editors committed to an internal peer review of their editorial processes to mitigate such bias in the future. ${ }^{13}$ Authors of a paper in the Annals of Thoracic Surgery apologized for including a derogatory image emblematic of systemic racism. ${ }^{14}$ All of these papers survived the peer-review and copyediting process intact. How did these massive oversights occur in our current era of inclusivity, and what is preventing them from being repeated?

First, the lack of diversity in the leadership of medical publishing is profound. When the majority of research papers and grants are reviewed by White, able-bodied, cisgender men in positions of power, there is a missed opportunity to capitalize on the experience and expertise of underrepresented groups, including (but not limited to) women and racialminority physicians. We reviewed the publicly available biographical sketches of the editorial boards of 5 Englishlanguage cardiovascular journals with high impact factors (Table 1). Gender was inferred by assessing the pronouns utilized in the biographical sketches. We found that White men make up the greatest proportion of editorial board members. Racial-minority women were the least represented. This lack of diversity of experience creates editorial knowledge gaps in the peer-review process through which biased sujet. Nous résumons également les difficultés auxquelles sont confrontés les femmes et les médecins issus des minorités raciales qui choisissent et mènent avec brio une carrière en cardiologie, de même que les obstacles systémiques à leur réussite. Au cours de la dernière décennie, les mouvements de justice sociale ont progressé. Les normes de professionnalisme évoluent, et tous les médecins doivent connaître et comprendre les avancées terminologiques. Dans le présent article, nous résumons les termes et les concepts clés, en y adjoignant des exemples propres au domaine de la cardiologie. Nous proposons aussi un nouveau paradigme de professionnalisme.

literature can slip. Perpetuating negative stereotypes in our medical journals harms members of our profession from equity-deserving groups who are already in the minority.

Second, recognizing that review bias exists is an important step in creating meaningful change. An assessment of funding success for grant and personnel applications to the major Canadian health research funding agency (Canadian Institutes of Health Research) found that women who directed funding applications to the Circulatory and Respiratory Health Institute were significantly less likely to be funded than their male colleagues. ${ }^{15}$ Women who submitted grants to this institute, where most cardiology grants are directed, had the lowest success rate, compared with all institutes, and the disparity persisted over the 15-year time period of the study. ${ }^{15}$ Similar research in the US found that women in academia held fewer grants, submitted fewer applications, and were less successful in receiving funding renewal. ${ }^{16}$ Further, when author names are masked from reviewers, the proportion of women who are successful increases. ${ }^{17}$ Altogether, these findings suggest gender bias in the peer-review process. Methodology for investigating the presence or absence of editorial bias, and mitigating it when it is present, has been published but has not yet been undertaken by most cardiology journals. ${ }^{17,18}$ This unaddressed inequity only compounds the problem that women physicians are awarded less career advancement than their male colleagues, independent of experience or research productivity. ${ }^{19}$

Beyond required competence in clinical and research skills, it is essential that cardiology professionals understand key terms and concepts of equity, diversity, and inclusion (Table 2). Confronting one's own implicit biases with knowledge, understanding, grace, and humility, plus directly challenging workplace discrimination, both overt and covert, is vital to the evolution of the profession and necessary to adequately serve a diverse patient population. Past definitions of professionalism often reinforce bias and are no longer valid in today's changing landscape. In Figure 1, characteristics used to define professionalism in the past have been contrasted with a reinterpretation through the lens of equity, diversity, and inclusion. Mechanisms by which this transition can be catalyzed are also suggested.

\section{A Review of the Literature on Cardiology Workforce Equity}

\section{Gender equity}

The most robust equity literature to date in cardiology explores the experiences of women cardiologists. Important to 
Table 1. Makeup of the editorial boards of several high-impact factor cardiac sciences journals

\begin{tabular}{|c|c|c|c|c|c|}
\hline \multirow[b]{2}{*}{ Journal } & \multirow{2}{*}{$\begin{array}{c}\text { Total number of editorial board } \\
\text { members }\end{array}$} & \multicolumn{4}{|c|}{ Editorial board members, $\mathrm{n}(\%)^{*}$} \\
\hline & & White men & White women & Racial-minority men & Racial-minority women \\
\hline European Heart Journal & 105 & $67(64)$ & $21(20)$ & $13(12)$ & $4(4)$ \\
\hline Circulation & 44 & $21(48)$ & $5(11)$ & $10(23)$ & $8(18)$ \\
\hline$J A C C$ & 24 & $18(75)$ & $4(17)$ & $2(8)$ & $0(0)$ \\
\hline Circulation Research & 21 & $4(19)$ & $8(38)$ & $6(29)$ & $3(14)$ \\
\hline Nature Reviews Cardiology & 40 & $16(40)$ & $7(18)$ & $9(23)$ & $8(20)$ \\
\hline
\end{tabular}

JACC, Journal of the American College of Cardiology.

* Estimations of race and gender were made based on institutional profiles (pronouns) and images of editorial board members available on the Internet. We recognize the inherent weakness of this methodology and the high probability of misclassification error. Therefore, we present these data as estimations valuable only in their ability to exhibit trends.

${ }^{\dagger}$ Editors, deputy editors, and associate editors were included; section editors and guest editors were excluded.

note is that most cardiology publications regarding career choice, pregnancy, and gender discrimination in the workplace use the terms "female" and "woman" interchangeably, and often report sex data as gender data. Sex is generally assigned at birth in a binary fashion, despite the established inaccuracy of this approach. Gender is a social construct with multiple dimensions, including identity, expression, and roles. Like sex, gender exists on a spectrum and may change over time. As yet, no data have been collected regarding the experiences of sex- and gender-diverse people training and working in the cardiac sciences.

Over the past 3 decades, despite more women than ever graduating from medical schools in North America, the proportion of women practicing cardiology has never surpassed 25\%. 1,20,21 Even among cardiology trainees, men are significantly more likely (odds ratio: 3.98 ) to enter an interventional specialty than are women. ${ }^{22}$ Despite career satisfaction among women cardiologists being high, women trainees have repeatedly cited lack of accommodations for pregnancy and parenting, an unsafe work environment for women (ie, with sexist language, overt gender discrimination, and sexual harassment), and poor work-life integration as reasons to choose other specialties. $3,20,22,23$

Unfortunately, the concerns of the meritorious woman internist who is interested in cardiology but chooses another specialty to avoid discrimination are not unfounded. The suggestion has been made that cardiology has an "image problem," which is true, but that image is not just a mirage. ${ }^{24}$ The results of a survey of advanced cardiology trainees at the Mayo Clinic revealed a negative stigma relating to pregnancy, as identified by trainees, a lack of flexibility for training and parenting responsibilities, and a lack of support for breastfeeding beyond a baby's 6th month of life. ${ }^{25}$ A large disparity exists when cardiology trainees ask for parental leave; 69\% of trainee fathers reported favourable treatment, but none of the trainee mothers experienced favourable responses. ${ }^{25}$ This discrepancy is a significant problem because the average woman who pursues a career in cardiology either has children during training or plans on having children in the early career phase.

A large proportion of women cardiologists used assisted reproductive technology to conceive, indicating that a delay in childbearing has significant fertility repercussions. ${ }^{4}$ Only $3 \%$ of women cardiologists took 6 months or more of maternity leave, and the majority failed to meet breastfeeding recommendations. Women identified pressure from colleagues as a factor in their taking less leave than that available to them. ${ }^{4}$
Even though the majority of women working in cardiology are, or will become, working mothers, knowledge and procedures regarding radiation exposure are significantly lacking. 4,23,26

If a woman internal medicine resident makes the choice to forgo children, hurdles remain if she chooses cardiology. Using an administrative dataset, US researchers found that, after correction for job duties and productivity metrics, women cardiologists had a yearly pay gap of $\sim \$ 30,000$ (US), compared with men. Women had lower patient and procedural volumes but additional, traditionally non-compensated, work was not evaluated. ${ }^{27}$ These well-documented genderbased pay disparities, seen in every medical specialty, are not the result of working less, being a parent, academic productivity, career track, practice setting, or choice. ${ }^{28}$ Women consistently work in more academic settings where research and teaching take up a greater proportion of their time than that of their male colleagues. ${ }^{26}$ In addition to being paid less than men, fewer women in cardiology achieve the rank of full professor. This disparity persists even when correcting for experience and research productivity. ${ }^{19}$

If the indignities of less pay for equal work, discrimination in the peer-review process, and delayed advancement do not dissuade women from pursuing cardiology careers, the prevalence of sexual harassment might. In a recent United Kingdom study, $35.7 \%$ of women cardiology consultants experienced unwanted sexual comments or advances from senior colleagues. ${ }^{6}$

Assertions that gender discrimination will gradually vanish with the retirement of "old-fashioned" colleagues are unfounded. The effect of gender on grant application success did not lessen over a 15-year time period. ${ }^{15}$ The incidence of women candidates being asked whether they planned to have children, during a work-related interview at some stage of their career, an illegal question, did not decline over time. ${ }^{4}$ No changes or improvements in professional advancement disparities have occurred over time. ${ }^{19}$ A total of $71 \%$ of women cardiologists reported sex discrimination in their workplace in 1996 , and $65 \%$ reported the same problem in $2015 .^{26}$ Unfortunately, the problem of gender discrimination in the cardiac sciences is not one that is improving passively over time.

\section{Racial equity}

We would be remiss if we did not start this segment of our review by acknowledging that race is a social construct that is not easily defined with mutually exclusive categories. Terms 
Table 2. Key concepts that all cardiac sciences professionals should understand

\begin{tabular}{|c|c|c|}
\hline Term/concept & Definition & Cardiac sciences example \\
\hline Equity & $\begin{array}{l}\text { An upgrade to the concept of equality-rather than } \\
\text { treating everyone the same, we recognize that different } \\
\text { groups of people have different challenges, and we } \\
\text { support colleagues with the resources they need to } \\
\text { succeed }\end{array}$ & $\begin{array}{l}\text { A woman trainee does not do overnight calls for the last } 3 \text { months of } \\
\text { her pregnancy. She is not forced to do extra coronary care unit calls } \\
\text { when she returns from maternity leave, even if this means she does a } \\
\text { few less shifts overall than her male colleagues during her training } \\
\text { program. This is because we value women in our workforce and } \\
\text { appreciate that women have different strengths and challenges than } \\
\text { men. }\end{array}$ \\
\hline $\begin{array}{l}\text { Commitment to } \\
\text { diversity in medicine }\end{array}$ & $\begin{array}{l}\text { Acknowledging that people coming together with different } \\
\text { backgrounds and perspectives leads to improved patient } \\
\text { care for the diverse population we serve }\end{array}$ & $\begin{array}{l}\text { A division lead notes that there are few Indigenous members of their } \\
\text { physician workforce and recognizes this as a weakness. They create a } \\
\text { program to mentor Indigenous trainees and encourage their interest } \\
\text { in cardiac sciences. When they post academic job postings, they } \\
\text { state a commitment to diversity and a preference for candidates from } \\
\text { equity-deserving groups. }\end{array}$ \\
\hline Microaggressions & $\begin{array}{l}\text { Subtle snubs, slights, and insults directed toward those in } \\
\text { the minority, including dismissive body language and } \\
\text { tone of voice that imply disrespect, devaluation, and } \\
\text { exclusion }\end{array}$ & $\begin{array}{l}\text { A white physician tells a Latino junior colleague that he must check the } \\
\text { "Hispanic" box on his grant application if he wants success. This is a } \\
\text { microinsult, as it suggests the junior colleague cannot achieve } \\
\text { success without affirmative action programs and that he is, therefore, } \\
\text { "less qualified" than other White applicants. }\end{array}$ \\
\hline Implicit bias & $\begin{array}{l}\text { Associations outside conscious awareness that lead to a } \\
\text { negative evaluation of a person based on irrelevant } \\
\text { characteristics, such as race or gender }{ }^{40}\end{array}$ & $\begin{array}{l}\text { An Indigenous woman with a history of opioid dependency presents } \\
\text { with chest pain and myocardial infarction. Because of settler- } \\
\text { colonialism and racial implicit bias, the triage nurse guesses she is } \\
\text { "drug-seeking," which delays initial electrocardiogram and troponins } \\
\text { and subsequent care. }\end{array}$ \\
\hline Explicit bias & $\begin{array}{l}\text { Conscious and overt preferences for groups based on race } \\
\text { or gender; this includes traditionally accepted concepts } \\
\text { of racism and/or sexism }\end{array}$ & $\begin{array}{l}\text { A staff cardiologist tells a woman trainee that she should not pursue a } \\
\text { career in cardiology because women are not strong enough to handle } \\
\text { the intense call responsibilities required. }\end{array}$ \\
\hline Privilege & $\begin{array}{l}\text { Unearned advantage conferred by invisible systemic forces } \\
\text { (sexism, heterosexism, racism, ableism, settler } \\
\text { colonialism, and classism) that benefit some social } \\
\text { groups over others }\end{array}$ & $\begin{array}{l}\text { A cardiologist of Southeast Asian descent enters rounds late after they } \\
\text { were delayed by a sick patient. As they enter, they wonder if their } \\
\text { mostly White colleagues will be judging them and attributing their } \\
\text { lateness to unfair stereotypes about their race. A White woman } \\
\text { cardiologist enters a few minutes later for a similar reason. Most of } \\
\text { her colleagues in the room are of the same racial group as she is, and } \\
\text { she is privileged to know that her lateness will be attributed to being } \\
\text { busy and not generalizations about her race. }\end{array}$ \\
\hline
\end{tabular}

like BIPOC (Black, Indigenous, and people of colour), Asian, and underrepresented minorities are all problematic, as they clumsily lump together disparate groups with very different experiences and perspectives. Intersections are also present between different forms of privilege and unearned disadvantage that can seem nebulous and hard to quantify. ${ }^{29}$ The small body of literature on racial diversity and equity in the cardiac sciences, which we summarize here, carries all of these limitations.

More than $50 \%$ of cardiologists in the US are White. ${ }^{2}$ The American Heart Association, recognizing this lack of diversity, has provided a call to action to encourage more members of underrepresented minorities (defined as Blacks, Mexican Americans, mainland Puerto Ricans, and Indigenous Americans) to pursue careers in cardiovascular sciences. ${ }^{11}$ Members of underrepresented minorities are more likely to serve members of their own communities and could improve documented health disparities in these groups. They provide important cultural safety to patients of similar racial backgrounds and help their colleagues achieve cultural competency in caring for equity-deserving populations. ${ }^{11}$

The increased social consciousness of systemic racism has not bypassed the field of academic medicine, and awareness of antiracist principles is slowly improving. Despite these marginal advances, only a paucity of data is available on the professional experiences of racial-minority cardiologists. Data on the experiences of Black physicians in Canada suggests that explicit racism from colleagues and patients was common, and that systemic barriers in medical school and the medical workplace led them to have disparate experiences. ${ }^{30}$ Proponents of antiracism in the field of medicine highlight the need for deep listening. Research funding is required to create an evidence base on racism in the cardiology workforce that can then inform solutions. ${ }^{5}$

Despite the scarcity of literature detailing the effect of racism on cardiac science professionals, there are intermittent bright lights of progress. Leaders of a cardiology fellowship training program at The Ohio State University have published a successful framework for increasing racial diversity among trainees. ${ }^{31}$ In the 40 years prior to instituting the diversity program, they had not trained one underrepresented minority student. By making changes to their recruitment strategy (reaching out specifically to underrepresented minority trainees and creating a mentorship program for such applicants), they were able to drastically increase the number of underrepresented trainees in their program over a short period of time. ${ }^{31}$ These leaders have shown that antiracist policies can have a large impact on the cardiology workforce.

\section{Lesbian, gay, bisexual, transgender, queer/questioning, intersex, asexual (LGBTQIA) equity, religious equity, weight bias, and settler-colonialism equity}

Unfortunately, our review of the scientific literature found no original research or society position statements examining the impact of inequities not related to gender or race on the 


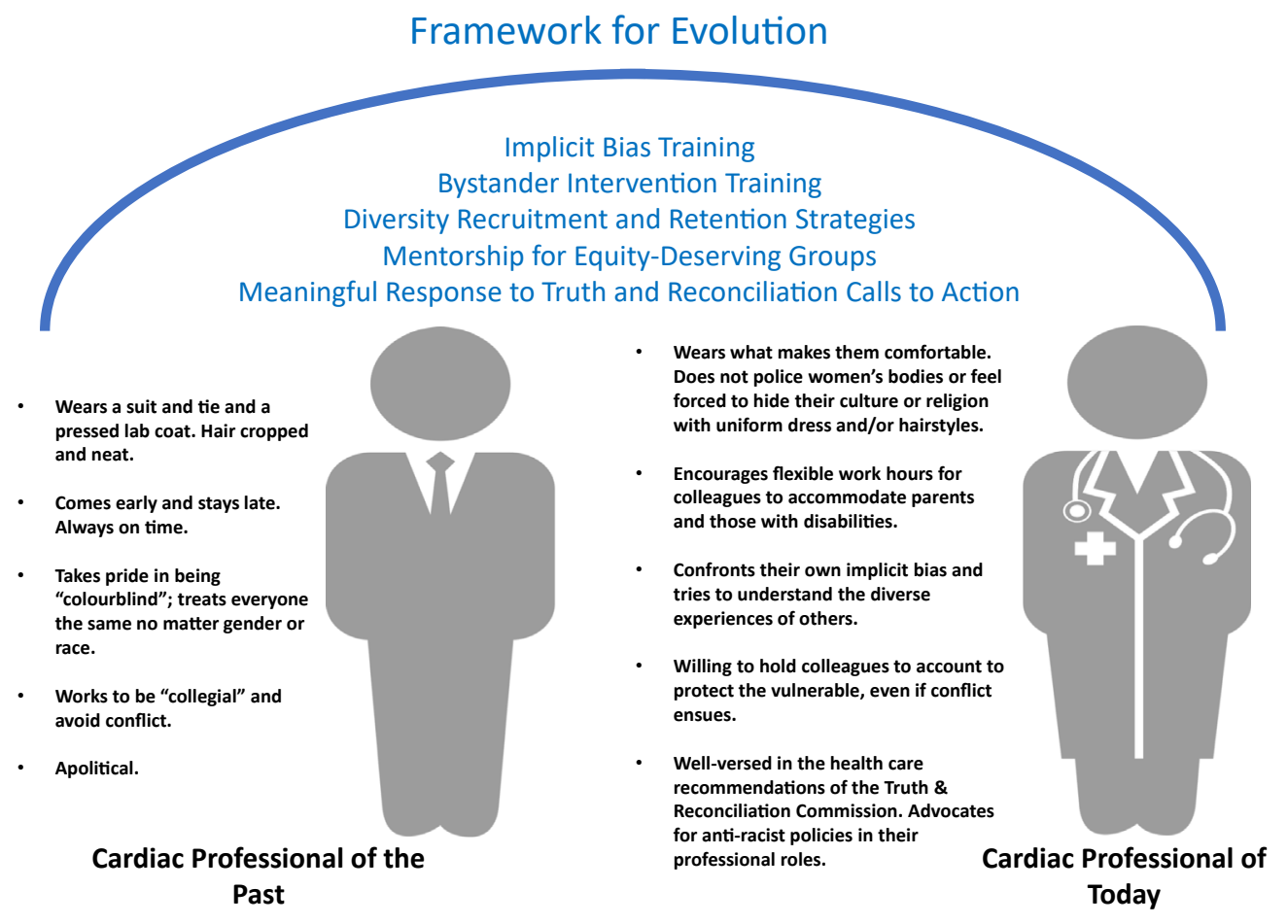

Figure 1. Redefining professionalism in the 21st century.

cardiology workforce. This presents a gap in the literature and an important area for future study.

\section{Future Directions}

Professional societies and groups of cardiologists belonging to equity-deserving groups have recognized the need for diversity in our profession. They have written position statements and provided suggestions for forward momentum., 11,21,32 But creating an equitable and inclusive profession cannot be achieved with the work of only the motivated few. Leaders in cardiovascular medicine need to do the hard work of confronting their own implicit biases, listening to those affected by bias and discrimination, and dismantling the systems that maintain the status quo of inequity and unearned privilege in our workforce. Research into the downstream effects of discrimination, microaggressions, and bias in the workplace is overdue to prevent the burnout and loss of physicians in equity-deserving groups. A new paradigm of professionalism is needed, and one that is proposed is illustrated in Figure 1.

Specific strategies to improve workforce equity include implicit bias training for all healthcare professionals, with the aim of illuminating and confronting unearned advantage in the workplace. This training should be combined with translational research investigating its downstream effects on patient care. ${ }^{33}$ Bystander intervention training workshops have been created and validated to reduce discrimination in healthcare settings and embolden physicians to confront the implicit and explicit biases of colleagues. ${ }^{34}$ In Canada, the National Centre for Truth and Reconciliation has created specific calls to action for healthcare professionals. ${ }^{35}$ All cardiologists should respond to these calls to action and familiarize themselves with the resources provided therein to improve the care of the Indigenous patients we serve. ${ }^{1}$

In addition to improving the equity-related knowledge of practicing cardiologists, the American Heart Association has identified the recruitment and retention of underrepresented candidates in the field of cardiology as a priority. ${ }^{2}$ Medical schools in the US that have created intentional diversity programs have improved recruitment and graduation of Black physicians; similar paradigms could be used in cardiology. ${ }^{36}$ In addition to increasing recruitment, retention of underrepresented colleagues, through provision of cultural safety, requires clear consequences for perpetrators of discrimination. Adequate mentorship of women in cardiology and the presence of racial-minority physicians have been identified as harbingers of success.

\section{Conclusions}

A growing body of literature describes inequities in the cardiology workforce. Most of the published research lays bare the gender disparities faced by women cardiologists. The available literature makes clear the fact that we are failing in our just mandate to create safe and supportive spaces for all our colleagues and patients in the field of cardiology. We are also missing the many opportunities afforded by diversity and inclusion, which foster empathy and personal evolution for all. Standards need to change, so that perpetuating discrimination, either explicitly or implicitly, becomes a rarity instead of the norm. Recent retractions of biased research have exposed the lack of diversity in the peer-review process. Standards of medical professionalism can change and should change to reflect principles of equity, diversity, and inclusion. Leaders in 
cardiovascular medicine must take urgent and meaningful action and adopt them.

\section{Funding Sources}

The authors have no funding sources to declare.

\section{Disclosures}

The authors have no conflicts of interest to disclose.

\section{References}

1. Canadian Medical Association. Number and percent distribution of physicians by specialty and sex, Canada 2018. Available at: https://www. cma.ca/sites/default/files/2019-03/2018-06-spec-sex.pdf. Accessed May $1,2021$.

2. Johnson AE, Talabi MB, Bonifacino E, et al. Racial diversity among American cardiologists: implications for the past, present, and future. Circulation 2021;143:2395-405.

3. Douglas PS, Rzeszut AK, Bairey Merz CN, et al. Career preferences and perceptions of cardiology among US internal medicine trainees: factors influencing cardiology career choice. JAMA Cardiol 2018;3:682-91.

4. Sarma AA, Nkonde-Price C, Gulati M, et al. Cardiovascular medicine and society: the pregnant cardiologist. J Am Coll Cardiol 2017;69: 92-101.

5. Yancy CW. Academic medicine and black lives matter: time for deep listening. JAMA 2020;324:435-6.

6. Jaijee SK, Kamau-Mitchell C, Mikhail GW, Hendry C. Sexism experienced by consultant cardiologists in the United Kingdom. Heart 2021;107:895-901.

7. Stratton TD, McLaughlin MA, Witte FM, Fosson SE, Nora LM. Does students' exposure to gender discrimination and sexual harrassment in medical school affect specialty choice and residency program selection? Acad Med 2005;80:400-8.

8. Glauser W. Does medical professionalism have a dark side? CMAJ 2020;192:E1646-7.

9. Hardouin S, Cheng TW, Mitchell EL, et al. RETRACTED: prevalence of unprofessional social media content among young vascular surgeons. J Vasc Surg 2020;72:667-71.

10. ( RETRACTED), Wang NC. Diversity, inclusion, and equity: evolution of race and ethnicity considerations for the cardiology workforce in the United States of America From 1969 to 2019. J Am Heart Assoc 2020;9: e015959.

11. Francis CK, Alpert JS, Clark LT, Ofili EO, Wong RC. Working group 3: how to encourage more minorities to choose a career in cardiology. J Am Coll Cardiol 2004;44:241-5.

12. Burgart AM, Pendergrast T. Poorly conducted science is unprofessional. J Vasc Surg 2020;72:1828-9.

13. Elkind MSV, Harrington RA, Lloyd-Jones DM. A path forward. J Am Heart Assoc 2020;9:e019210.

14. Chow OS, Sudarshan M, Maxfield MW, et al. Regarding an offensive figure in the manuscript titled "National Survey of Burnout and Distress Among Cardiothoracic Surgery Trainees.". Ann Thorac Surg 2021. https://doi.org/10.1016/j.athoracsur.2021.06.011 [e-pub ahead of print].

15. Burns KEA, Straus SE, Liu K, Rizvi L, Guyatt G. Gender differences in grant and personnel award funding rates at the Canadian Institutes of
Health Research based on research content area: a retrospective analysis. PLoS Med 2019;16:e1002935.

16. Hechtman LA, Moore NP, Schulkey CE, et al. NIH funding longevity by gender. Proc Natl Acad Sci U S A 2018;115:7943-8.

17. Budden AE, Tregenza T, Aarssen LW, et al. Double-blind review favours increased representation of female authors. Trends Ecol Evol 2008;23: $4-6$.

18. Edwards HA, Schroeder J, Dugdale HL. Gender differences in authorships are not associated with publication bias in an evolutionary journal. PLoS One 2018;13:e0201725.

19. Jena AB, Khullar D, Ho O, Olenski AR, Blumenthal DM. Sex Differences in academic rank in US medical schools in 2014. JAMA 2015;314: $1149-58$.

20. Warnes CA, Fedson SE, Foster E, et al. Working group 2: how to encourage more women to choose a career in cardiology. J Am Coll Cardiol 2004; $44: 238-41$.

21. Lau ES, Wood MJ. How do we attract and retain women in cardiology? Clin Cardiol 2018;41:264-8.

22. Yong CM, Abnousi F, Rzeszut AK, et al. Sex differences in the pursuit of interventional cardiology as a subspecialty among cardiovascular fellowsin-training. JACC Cardiovasc Interv 2019;12:219-28.

23. Capranzano P, Kunadian V, Mauri J, et al. Motivations and barriers to choosing an interventional career path: results from the EAPCI Women Committee worldwide survey. EuroIntervention 2016;12:53-9.

24. Wenger NK. Women in cardiology: the US experience. Heart 2005;91: 277-9.

25. Mwakyanjala EJ, Cowart JB, Hayes SN, Blair JE, Maniaci MJ. Pregnancy and parenting during cardiology fellowship. J Am Heart Assoc 2019;8: e012137.

26. Lewis SJ, Mehta LS, Douglas PS, et al. Changes in the professional lives of cardiologists over 2 decades. J Am Coll Cardiol 2017;69:452-62.

27. Jagsi R, Biga C, Poppas A, et al. Work activities and compensation of male and female cardiologists. J Am Coll Cardiol 2016;67:529-41.

28. Cohen M, Kiran T. Closing the gender pay gap in Canadian medicine. CMAJ 2020;192:E1011-7.

29. Nixon SA. The coin model of privilege and critical allyship: implications for health. BMC Public Health 2019;19:1637.

30. Mpalirwa J, Lofters A, Nnorom O, Hanson MD. Patients, pride, and prejudice: exploring Black Ontarian physicians' experiences of racism and discrimination. Acad Med 2020;95 (11S Association of American Medical Colleges Learn Serve Lead: Proceedings of the 59th Annual Research in Medical Education Presentations):S51-S57.

31. Auseon AJ, Kolibash AJ Jr, Capers Q. Successful efforts to increase diversity in a cardiology fellowship training program. J Grad Med Educ 2013;5:481-5.

32. Sharma G, Sarma AA, Walsh MN, et al. 10 recommendations to enhance recruitment, retention, and career advancement of women cardiologists. J Am Coll Cardiol 2019;74:1839-42.

33. Hagiwara N, Kron FW, Scerbo MW, Watson GS. A call for grounding implicit bias training in clinical and translational frameworks. Lancet 2020;395:1457-60.

34. Relyea MR, Portnoy GA, Klap R, et al. Evaluating bystander intervention training to address patient harassment at the Veterans Health Administration. Womens Health Issues 2020;30:320-9. 
35. National Centre for Truth and Reconciliation. Truth and reconciliation calls to action. Available at: https://nctr.ca. Accessed June 2021.

36. Sullivan LW. A check-up on Blacks in US medical schools. J Blacks High Educ (2005) 1-1. Available at: https://www.jbhe.com/features/47_medical schools.html. Accessed May 1, 2021.

37. Caterini JE, Adreak N, Cheung CC, et al. Opportunities for advancing mentorship: highlighting early career transitions for women in cardiovascular medicine and science. Can J Cardiol 2021;37:176-9.
38. Sensoy Ö Diangelo RJ. "We are all for diversity, but ...": how faculty hiring committees reproduce whiteness and practical suggestions for how they can change. Harvard Educ Rev 2017;87:557-80.

39. Torres MB, Salles A, Cochran A. Recognizing and reacting to microaggressions in medicine and surgery. JAMA Surg 2019;154:868-72.

40. FitzGerald C, Hurst S. Implicit bias in healthcare professionals: a systematic review. BMC Med Ethics 2017;18:19. 